\title{
O TRABALHO DE ASSISTENTES SOCIAIS EM UMA UNIDADE DE CUIDADOS PALIATIVOS
}

\author{
Tainara da Rosa $^{1}$ \\ Ângela Maria Pereira da Silva ${ }^{2}$
}

\section{Introdução}

Tratar sobre a morte e acompanhar o processo de adoecimento de um paciente, bem como o impacto sobre os seus familiares na perspectiva do cuidado paliativo, surge como uma demanda emergente para os/as assistentes sociais na política de saúde, em especial, em hospitais. $\mathrm{O}$ fortalecimento dos familiares e pacientes para $\mathrm{o}$ enfrentamento deste processo é fundamental, através do conhecimento sobre cuidados paliativos e da possibilidade de dialogar a respeito da finitude como sendo um processo natural e intrinsecamente ligado à vida. A intervenção do assistente social ganha ênfase nessas abordagens, pois o acesso às informações acerca dos direitos fazem parte desta inter-relação entre os sujeitos implicados.

Assim, torna-se uma contribuição relevante escrever sobre este tema, visto que apesar de crescente, ainda há pouca produção científica devido os cuidados paliativos serem recentes no Brasil. Porém, vem ganhando espaço e se torna ímpar para o meio acadêmico e profissional tais produções científicas, para utilizarmos como um aporte teórico e prático. Diante disso, o objetivo é contextualizar acerca do trabalho de assistentes sociais em uma unidade de cuidados paliativos com usuários internados e seus familiares/cuidadores.

Retratar-se-á essa experiência de estágio em Serviço Social na Unidade Álvaro Alvim (UAA), na unidade de cuidados paliativos, com base na corrente teórica materialista dialética crítica e em autores como Vasconcelos (2009; 1997), Mota (2009), Bravo (2015; 2009), Martinelli (2011; 2007), Iamamoto (2007; 2004), Andrade (2017; 2007), Matos (2020; 2009), entre outros.

\section{Metodologia}

\footnotetext{
${ }^{1}$ Universidade Luterana do Brasil. E-mail: tainaradarosa7@ hotmail.com. ORCID: https://orcid.org/00000002-0749-1557

2 Universidade Luterana do Brasil. E-mail: angela.silva@ulbra.br. ORCID: https://orcid.org/0000-00018793-4620
}

Iluminuras, Porto Alegre, v. 22, n. 58, p. 402-423, dezembro, 2021 
Trata-se de um relato de experiência com base em uma pesquisa descritiva ${ }^{3}$ com abordagem qualitativa, baseado na teoria crítica marxista, a partir de observação participante, considerando as vivências da autora durante o estágio em Serviço Social em uma unidade de cuidados paliativos. Foram utilizados os seguintes instrumentos para o levantamento de dados, além da escuta sensível, observação, grupos com os familiares, distribuição de folder informativo a respeito de cuidados paliativos, registros no diário de campo, análise institucional, relatórios descritivos e condensados, preenchimento de ficha para entrevista e avaliação sociofamiliar, produzidos durante o estágio.

Neste período foram acompanhados 32 pacientes, sendo 17 mulheres(53\%) e 15 homens (47\%), destes 12 tinham idade entre 60 a 69 anos (38\%), 8 com idade entre 50 e 59 anos (25\%), 5 com idade entre 80 e 89 anos (16\%), 4 com idade entre 70 e 79 anos (13\%), e 3 com idade entre 40 e 49 anos (9\%), o diagnóstico que mais prevaleceu entre os pacientes acompanhados foi a neoplasia maligna, mais conhecido como câncer, sendo esse entre 29 pacientes (91\%), 1 paciente com diagnóstico de Lúpus (3\%), 1 com Acidente Vascular Cerebral (3\%), e 1 com diagnóstico de Septicemia não especificada (3\%), quanto à escolaridade, 15 pacientes possuíam ensino fundamental incompleto (47\%), 6 ensino médio completo (19\%), 4 sem escolaridade (13\%), 3 com ensino médio incompleto (9\%), 2 com ensino fundamental completo (6\%), 1 com ensino superior incompleto (3\%), e 1 com ensino superior completo (3\%), referente a renda destes pacientes, 21 estavam aposentados (66\%), 5 não possuíam renda (16\%), 4 recebiam auxílio doença (13\%), 1 recebia o Benefício de Prestação Continuada (3\%), e 1 possuía vínculo trabalhista como servente de escola (3\%), sobre a cidade onde residiam os pacientes, 22 em Porto Alegre (69\%), 2 em Viamão (6\%), 1 em Amaral Ferrador (3\%), 1 em Gravataí (3\%), 1 em Alvorada (3\%), 1 em Capão da Canoa (3\%), 1 em Osório (3\%), 1 em Campo Bom (3\%), 1 em Esteio (3\%) e 1 em Guaíba (3\%).

Estes dados foram levantados durante o reconhecimento dos usuários em acompanhamento na respectiva unidade de cuidados paliativos. Para esse estudo buscou-se respaldo no pensamento dialético crítico para fundamentar teoricamente o

\footnotetext{
3 Pesquisas descritivas vão além da simples identificação da existência de relações entre variáveis, pretendendo determinar a natureza dessa relação. Existem pesquisas que, embora definidas como descritivas, a partir de seus objetivos, acabam servindo mais para proporcionar uma nova visão do problema, o que as aproxima das pesquisas exploratórias. (GIL,1991:46).
} 
processo de trabalho de assistentes sociais.

\section{Determinantes sociais da saúde como desdobramentos da questão social na vida de usuários em cuidados paliativos}

Presencia-se um contexto histórico em que as novas descobertas e os avanços tecnológicos na área da saúde permitem com que se viva por mais tempo, à medida que “[...] muitas doenças mortais se transformassem em doenças crônicas, levando à longevidade dos portadores dessas doenças" (Matsumoto, 2012: 23). Mediante a essa realidade, tem-se a ascensão deuma especialidade chamada "Cuidados Paliativos". Esta denominação surge como possibilidade terapêutica aos/às pacientes acometidos/as de diagnósticos que põem em risco a vida e se propõe ao alívio da dor e demais sintomas. Também, acolher de forma humanizada os indivíduos e suas famíliasde modo a fortalecer a dignidade das mesmas e a integralidade do cuidado (Matsumoto, 2012).

A Organização Mundial de Saúde (OMS) definiu em 1990, revisou em 2002 e mais recentemente em 2017 a definição de "cuidado paliativo" como:

\footnotetext{
(...) uma abordagem que melhora qualidade de vida de pacientes (adultos e crianças) e seus familiares que estão enfrentando problemas associados a doenças que ameacem a vida. Previne e alivia o sofrimento através da identificação precoce, avaliação correta e tratamento da dor e outros problemas, sejam físicos, psicossociais e espirituais. (OMS, 2017).
}

Os cuidados paliativos surgiram oficialmente como prática distinta na área da atenção à saúde na década de 1960, no Reino Unido, tendo como pioneira a médica Cicely Saunders (Du Boulay, 2007). O trabalho dessa médica precursora, que também era assistente social e enfermeira, iniciou o movimento dos cuidados paliativos, que inclui a assistência, o ensino e a pesquisa.

Nessa perspectiva, a autora aponta que Saunders desenvolveu o termo "Dor Total", quando percebeu que os pacientes que apresentavam dor física, tinham outros problemas associados, como sofrimentos espirituais, emocionais e sociais. Isso tudo, pode afetar o paciente perante o seu núcleo familiar, entre tantas questões que ocorrem durante o adoecimento, assim, se esses não fossem associados e considerados, o controle da dor física não era possível deser feito.

Esses pacientes precisavam de uma equipe multiprofissional, de modo que todos

Iluminuras, Porto Alegre, v. 22, n. 58, p. 402-423, dezembro, 2021 
os aspectos: físicos, psicológicos, espirituais e sociais, fossem vistos na perspectiva da integralidade, e é neste cenário que apresenta-se a importância do trabalho do assistente social em cuidados paliativos. Pode-se perceber isso, a partir dos relatos extraídos do diário de campo, do paciente $\mathrm{D}^{* 4}$ (65 anos) com câncer de esôfago, na primeira abordagem particular sobre suas relações familiares, ao referir o distanciamento da família, ele cita entre alguns dos possíveis motivos para tal, o seu uso excessivo de álcool.

Até 1980 éramos muito próximos, mas depois foi como uma panela de pressão, que estourou e cada um foi pra um lado. [...] Antes as coisas eram diferentes. (Rosa, 2019, extraído do Diário de Campo).

$\mathrm{Na}$ sequência, tratou-se do seu processo de adoecimento e como sentia-se naquele momento:

Estou cansado, com dor. [...] Dor de muitas coisas. [...] É tudo junto. (Rosa, 2019, extraído do Diário de Campo).

Assim, podemos relacionar o conceito de Dor Total com a narrativa do paciente, para além do seu sofrimento físico diante da doença, ele nos traz sobre o distanciamento da família, que se faz pouco presente durante a sua internação. Isso se deve às questões de trabalho de alguns, outros por residirem longe, e também devido aos vínculos fragilizados. Para compreender melhor a convivência familiar deste paciente, foram necessários atendimentos a sua companheira, quem mais esteve presente durante a internação.

Desse modo, no campo de estágio, foi perceptível a importância do atendimento integral, uma vez que os atendimentos eram extensivos à rede familiar e socioassistencial no apoio aos pacientes, diante da importância de acolher, escutar, orientar, encaminhar de forma assertiva à viabilização de direitos. Destacam-se, desde os benefícios previdenciários, articulação com a rede intersetorial do município de origem, orientações para o auxílio funeral, translado e a doação de corpos para estudos em universidades.

Por isso, o trabalho do assistente social na equipe de cuidados paliativosenvolve o conhecimento da história de vida do usuário por meio da inter-relação com as famílias que conjuntamente participam desse processo e sofrem os rebatimentos da 
questão social entendidas como os DSS. Para a Comissão Nacional sobre os Determinantes Sociais da Saúde (CNDSS), DSS são considerados:

[...] os fatores sociais, econômicos, culturais, étnicos/raciais, psicológicos e comportamentais que influenciam a ocorrência de problemas de saúde e seus fatores de risco na população. (CNDSS, 2006).

Isso revela a importância do asseguramento de direitos sociais de pacientes e suas famílias para minimizar as repercussões impostas pela crise capitalista e consequentemente no rebatimento nas políticas de saúde. Portanto, compreender as inúmeras dificuldades que se colocam nesse processo de saúde-doença é necessário, por vezes, uma morte evitável. Ressalta-se a falta de ações de prevenção, promoção e proteção na saúde pública, a dificuldade no atendimento precoce, bem como a resistência de pacientes em acessarem os serviços de saúde mediante o agravamento da doença, de não haver espaços de acolhimento humanizado para atender o paciente e a família em sua integralidade.

Pode-se mencionar uma situação vivida em campo, onde a equipe médica sinaliza a necessidade do Serviço Social de acompanhar o paciente C* (59 anos), com câncer de esofago, pois este ainda estaria internado devido a seu município de origem não ter disponível a nutrição enteral ${ }^{5}$ que o mesmo precisava. Após realizar o acolhimento e a escuta desse paciente e de sua principal cuidadora e irmã $\mathrm{M}^{*}$ (50 anos), realizamos contato com a rede de saúde do seu território (Unidade Básica de Saúde, Farmácia Especial e Secretaria Municipal de Saúde), que nos confirmaram não haver a alimentação disponível naquele momento e que a previsão girava em torno de 30 dias ou mais.

Frente a isso, para evitar que $C^{*}$ tivesse seus direitos violados, encaminhamos relatório social aos órgãos competentes (Secretaria Municipal de Saúde, Centro de Referência em Assistência Social e Promotoria de DireitosHumanos). Neste caso, além do relatório, contamos com os registros no prontuário eletrônico a cada atendimento e o contato com os serviços da rede, sinalizando à equipe que o paciente ainda não tinha possibilidade de alta social.

Devido a condição clínica estável do paciente, não havia motivos pelo qual o mesmo permanecer internado, o que fez a equipe pressionar para $\mathrm{C}^{*}$ teralta. Contudo, a família não possuía recursos para arcar com a alimentação até que a fornecida pelo

Iluminuras, Porto Alegre, v. 22, n. 58, p. 402-423, dezembro, 2021 
município chegasse, o que justificou a necessidade da permanência social de $C^{*}$ na unidade. Isso alterou, à medida em que obtivemos a dieta através da AAPECAN Associação de Apoio a Pessoas com Câncer, e assim $C^{*}$ pode ter alta segura e com acesso aos recursos do qual necessitava.

Nesse contexto, o assistente social é um mediador no processo de transformação da realidade, e sua intencionalidade volta-se às diversas demandas sociais manifestadas como expressões da questão social, na vida dos pacientes e familiares na unidade de cuidados paliativos. Destacam-se os diversos tipos de violência vividos tanto pelo paciente quanto pelos familiares, situações de abuso, abandono, negligências, fragilização dos vínculos, pobreza, uso de substâncias psicoativas, não acesso aos direitos, bem como o desconhecimento sobre estes. Então, o processo implica em reconhecer que a prática profissional, como qualquer outra, possui um objeto, sobre o qual incide a sua ação; os meios, e o produto final, ou seja, seu resultado após a intervenção.

Desse modo, através do projeto ético político o assistente social tem como objeto de trabalho as múltiplas expressões da questão social. O conceito de questão social está diretamente vinculado ao modo de produção capitalista, com a precarização do trabalho, a industrialização, flexibilização dos direitos e o modo que a sociedade produz e redistribui a riqueza socialmente produzida. Para Couto (2009):

Todos os assistentes sociais, quando da ocupação de um espaço profissional, estão desafiados a estabelecer projetos de trabalho que possam lhes assegurar o reconhecimento do valor social de seu trabalho e que servirão de instrumento potente na busca de afirmação do projeto ético político profissional. (Couto, 2009: 12).

O sistema capitalista traz inúmeras contradições, entre elas está o modo de trabalho (produção), esse faz parte da sociedade, deve gerar conhecimentos, riquezas materiais, reconhecimento e desenvolvimento econômico. Contudo, a lógica do capital se torna, por vezes, degradada e alienada e perde a sua dimensão para atender as exigências do sistema. Iamamoto (2007) define ainda, questão social como:

A questão social expressa desigualdades econômicas, políticas e culturais das classes sociais, mediadas por disparidades nas relações de gênero, características étnico-raciais e formações regionais, colocando amplos segmentos da sociedade em situação de marginalidade em relação aos bens materiais e espirituais civilizatórios. (Iamamoto, 2007: 
160).

A partir desse direcionamento o assistente social tem se colocado nas diversas áreas de atuação, a fim de intervir para minimizar as mais distintas desigualdades, a exemplo da crise da política de saúde. Visto que vivenciamos um cenário que se agrava, fragilizando o já precário funcionamento do SUS e das demais políticas da seguridade social que neste momento estão sendo demandadas para ações emergenciais. Neste contexto, segundo Matos (2020), surgem novas situações em que os profissionais de saúde são convocados a intervir. No que se refere o Serviço Social, com base no artigo $3^{\circ}$, inciso d, do Código de Ética: "Participar de programas de socorro à população em situação de calamidade pública, no atendimento e defesas de seus interesses e necessidades" (CFESS, 2012).

O assistente social é um dos profissionais da saúde reconhecido pelo Conselho Nacional de Saúde pela Resolução nº 218 de 1997 e também pelo Conselho Federal de Serviço Social pela Resolução no 383 de 1999 (CFESS, 2010). Haja vista, que o assistente social é um dos profissionais aptos e competentes para atuar junto a equipe de Cuidados Paliativos. Nesse contexto,o assistente social deve ter presente que a morte e o luto são parte do seu cotidiano de trabalho.

Ao longo da história a representação da morte altera-se, antes o espaço familiar cedia a sala de casa para a cerimônia funeral, e na contemporaneidade, o ambiente hospitalar é o local rotineiramente da morte. Para Ariès:

\footnotetext{
A morte recuou e deixou a casa pelo hospital; está ausente do mundo familiar de cada dia. O homem de hoje, por não vê-la com muita frequência e muito de perto, a esqueceu; ela se tornou selvagem e, apesar do aparato científico que reveste, perturba mais o hospital, lugar de razão técnica, que o quarto da casa, lugar dos hábitos da vida quotidiana. (Ariès, 2003: 171).
}

Então, o processo de morrer que ainda é considerado um tabu na sociedade brasileira, nos leva a reflexão sobre a dignidade na morte, no conforto, no sentido que atribuímos à existência e na percepção deautorealização e não apenas na sobrevivência. Desse modo, a unidade de cuidados paliativos proporcionava tanto aos pacientes quanto aos profissionais, reflexões sobre a morte durante a internação. Nessa perspectiva, chama atenção a qualidade de vida ainda possível, além da importância da espiritualidade, as crenças ou religiões que cada qual possui nesse processo. 
Constatou-se muitos pacientes questionando a morte, e que antes não tiveram a oportunidade de pensar/falar sobre isso, o que corrobora para as sensações de medo, dor, culpa, solidão, entre outros. Isso era abordado pela equipe junto a esses pacientes, informando-os, trazendo tranquilidade, para compreenderem que os cuidados paliativos têm em seus princípios a morte digna, ou qualidade de morte, conforto, livre de dor, sem antecipá-la ou adiá-la. Conforme Pessini (2000):

\begin{abstract}
Não somos doentes e nem vítimas da morte. É saudável sermos peregrinos. Não podemos passivamente aceitar a morte que é consequência do descaso pela vida, causada pela violência, acidentes e pobreza. Podemos ser curados de uma doença classificada como sendo mortal, mas não de nossa mortalidade (Pessini, 2000: 170).
\end{abstract}

Ou seja, não podemos fugir da finitude, a morte está ligada à vida, e emcuidados paliativos, podemos auxiliar os usuários nessa perspectiva. Com isso, acompanhamos pacientes e familiares que possuem distintas formas de enfrentamento diante do processo de morrer, como registrados nas falas dos pacientes a seguir:

Como hoje eu tô bem, amanhã posso cair duro, eles precisam aceitar isso. (Rosa, 2019, Extraído do Diário de Campo).

Eu preciso aceitar, se não, eu vou antes que ele. (Rosa 2019, Extraído do Diário de Campo).

Na primeira fala temos o paciente J.* (63 anos), com câncer de esôfago, que fala abertamente sobre a morte, compreende a gravidade de sua doença e da não possibilidade de cura da mesma. Embora, seus filhos enfrentassem dificuldades em lidar com o adoecimento do pai. Já no segundo relato, temos a familiar A.* (89 anos), acompanhando o esposo L.* (86 anos), com câncer de próstata, A.* é uma familiar alegre, que mesmo diante da dor de ver o companheiro doente, vem aceitando seus limites. A mesma ressaltou sobre a necessidade de compreender e aceitar o processo, cuidando também de si, para melhor auxiliar L*, por vezes, ela até confortava os demais familiares.

Temos ainda, os relatos da paciente $C^{*}$ (55 anos), com câncer de reto, que diz não estar em sofrimento, porém preocupa-se com o marido, percebe nele dificuldade em lidar com o momento que estão passando. Na sequência temos o relato da paciente $\mathrm{P}^{*}$ 
(41 anos), com câncer de colo de útero, que

ainda possuía fé em sua recuperação, pois tinha desejos por realizar antes de partir e se mostrou preocupada com o filho caçula de 3 anos.

Eu não gritei, não chorei quando descobri, sabe, não sei se não caiu a ficha ainda ou o que. [..] Eu vejo ele (marido) assustado. (Rosa, 2020, Extraído do Diário de Campo).

Se eu tomar todas as medicações certinho, tenho certeza que Deus vai me curar. [...] Eu quero arrumar as coisas dele (filho), o quartinho. (Rosa, 2020, Extraído do Diário de Campo).

Conforme Kluber-Ross (1985), no momento da morte existem vários sentimentos que afloram nas mentes dos familiares, assim como nos pacientes, que sofrem a perda e passam pelo processo de elaboração da mesma: a negação do fato, o isolamento, a barganha, a depressão e a aceitação. Destaca-se o sentimento latente da raiva que acompanha este período, apesar de que, na maioria das vezes, não gostamos de admitir isso.

O luto não é um conjunto de sintomas que tem início após uma perda e, depois gradualmente se desvanece. Envolve uma sucessão de quadros clínicos que se mesclam e se substituem. (PARKES, 1998: 23).

Assim como os ossos quebrados podem se tornar mais fortes doque os não quebrados, a experiência de enlutamento pode fortalecer e trazer maturidade àqueles que até então estiveram protegidos de desgraças. A dor do luto é tanto parte da vida quanto a alegria de viver; é, talvez, o preço que pagamos pelo amor, o preço do compromisso (Parkes, 1998: 17).

Em 2018 através de uma pesquisa solicitada pelo Sindicato dos Cemitérios e Crematórios Particulares do Brasil (Sincep), identificou-se a percepção dos brasileiros frente a temas relacionados à morte, foram encontradas algumas bases que sustentam a necessidade de constantes intervenções em busca da abertura de nossa sociedade a questão da finitude. Entre os principais resultados, está a baixa presença do assunto no dia a dia: 74\% afirmam não falar sobre a morte no cotidiano. (Arantes, 2019). Reafirmando assim, os relatos ouvidos na unidade de cuidados paliativos e sinalizando sobre a importância da contribuição de assistentes sociais a partir da conversão dialógica sobre a morte.

Diante disso, o assistente social inserido no âmbito hospitalar, se faz necessário, porém durante seu processo de trabalho passa por dificuldades e limitações, entre esses, podemos citar a incompreensão do exercício profissional, às condições de

Iluminuras, Porto Alegre, v. 22, n. 58, p. 402-423, dezembro, 2021 
trabalho e/ou falta de conhecimento das competências dos assistentes sociais. Visto que, historicamente, esse profissional é requisitado para diversas ações que não são suas atribuições específicas. Nisso, percebemos uma alteração na visibilidade do assistente social nos espaços sócio-ocupacionais, como também foi visto na unidade de cuidados paliativos. Por isso, se faz necessário contextualizarmos de forma breve sobre a política de saúde no Brasil na sequência.

\section{Reflexões acerca da política de saúde após a lei 8080/1990}

Contextualizar-se-á de forma breve, a história das políticas de saúde no Brasil a partir da promulgação da Constituição Federal de 1988 como um marco legal e suas principais mudanças.

Ressalta-se como uma marco na história das políticas de saúde no Brasil em 1986 a VIII Conferência Nacional de Saúde em Brasília, tendo como tema central a discussão em torno da saúde como direito, a reformulaçãodo Sistema Nacional de Saúde e o financiamento setorial. Chama atenção a partir disso, o conceito ampliado de saúde e como direito de cidadania e dever do Estado. Ressalta-se a criação de instâncias institucionais de participação social, dos quais os debates emergiram a Associação Brasileira de Saúde Coletiva (ABRASCO), Centro Brasileiro de Estudos de Saúde (CEBES), Medicina Preventiva e Saúde Pública. Estas instituições assumiram outra dimensão a partir da participação de outras entidades representativas da população: moradores, sindicatos, partidos políticos, associações de profissionais e o parlamento.

Assim, a questão da saúde ultrapassou a análise setorial, referindo-se à sociedade como um todo, propondo-se não somente o Sistema Único, mas a Reforma Sanitária (BRAVO, 2009). Em 1987 foi implementado o Sistema Unificado e Descentralizado de Saúde (SUDS), como uma consolidação das Ações Integradas de Saúde

(AIS), que adotou como diretrizes a universalização e a equidade no acesso aos serviços, à integralidade dos cuidados, a regionalização dos serviços de saúde e implementação de distritos. Essa Conferência Nacional de Saúde corroborou para a promulgação da CF/1988, a mais avançada em termos sociais e políticos que o país já teve, afirmando a ampliação dos direitos sociais diante das desigualdades. A CF/1988 corresponde a um conjunto de normas que organiza os elementos constitutivos do Estado, objetivando declarar e garantir os direitos fundamentais (SLAIBI, 2010). 
Portanto, a CF/ 1988 representa as reivindicações advindas dos movimentos sociais e do período de redemocratização do país. Para Lobato e Giovanella (2012), desde a CF/1988, a saúde não é mais entendida apenas como uma manifestação biológica, mas principalmente, como uma construção social e coletiva. Assim, as formas de organização social, as condições de vida e de trabalho de uma dada sociedade são determinantes para a saúde. Diante disso, quanto mais desiguais forem essas condições de vida, mais desiguais serão os resultados em saúde das populações.

A saúde passa então, a ser declarada como um direito fundamental de cidadania, cabendo ao Estado a obrigação de provê-la a todos os cidadãos em consonância no Artigo 196:

A saúde é direito de todos e dever do Estado, garantindo mediante políticas sociais e econômicas que visem a redução do risco de doenças e de outros agravos e ao acesso universal e igualitário às ações e serviços para sua promoção, proteção erecuperação (CF 1988, Art. 196.).

A fim de materializar a saúde após o advento da CF/1988, foi criada aLei ${ }^{\circ}$ 8.080 de 1990 que regulamentou os Artigos 196 a 200. Tal lei é conhecida como Lei Orgânica da Saúde (LOS), que criou o Conselho Nacional da Saúde (CNS), responsável pela elaboração e discussão da política de saúde. A LOS regulou a gestão, definiu o financiamento do SUS, e também destaca-se a Lei $n^{\circ}$ 8132/90 que implementou as conferências e conselhos de saúde (Polignano, 2001: 22).

A partir de 1988 o conceito da seguridade social traz uma nova ideia, estabelecendo a formulação de um sistema de proteção social que abrangesse a universalidade de cobertura e o atendimento com equidade tanto às populações urbanas quanto rurais, na forma de participação do custeio, e com caráter democrático e descentralizado na gestão administrativa e participativa. (Carvalho, 2002). Cabe destacar entre as principais mudanças, a Lei nº 8.212/91 - Lei Orgânica da Seguridade Social, que institui que a política de saúde não depende mais de contribuição, pois é direito de todos e dever do Estado, sendo garantida mediante políticas sociais e econômicas que visam à redução do risco de doença e de outros agravos.

Essa lei preconiza ainda uma série de princípios dentre eles: o da universalidade de acesso aos serviços de saúde em todos os níveis de assistência; integralidade de assistência; preservação da autonomia das pessoas na defesa de sua integridade física e moral; igualdade da assistência à saúde; direito à informação; divulgação de

Iluminuras, Porto Alegre, v. 22, n. 58, p. 402-423, dezembro, 2021 
informações quanto ao potencial dos serviços de saúde e a sua utilização pelo usuário; utilização da epidemiologia para o estabelecimento de prioridades; participação da comunidade; descentralização político-administrativa e; integração em nível executivo das ações de saúde, meio ambiente e saneamento básico (BRASIL, 1990).

Ressalta-se que desde a criação do SUS houveram avanços em prol da saúde pública no Brasil, entretanto há desafios para que a integralidade preconizada na Lei $\mathrm{n}^{\circ}$ 8.080/90 se cumpra na vida da população usuária. Em relação a isso:

\begin{abstract}
Algumas questões comprometeram a possibilidade de avanço do SUS como política social, cabendo destacar: o desrespeito ao princípio da equidade dos recursos públicos pela não unificação dos orçamentos federal, estaduais e municipais; afastamento do princípio da integralidade, ou seja, indissolubilidade entre prevenção e atenção curativa, havendo prioridade para a assistência médico-hospitalar em detrimento das ações de promoção e proteção da saúde. (Bravo, 2009: 100).
\end{abstract}

Esse contexto é agravado pelo avanço do neoliberalismo a partir da década de 1990 no Brasil, que contribuiu para a retração dos direitos sociais. Inclusive no âmbito da política de saúde, as interferências do Fundo Monetário Internacional (FMI) e do Banco Mundial. Portanto, constata-se a crise do capitalismo, as mudanças nas regras de financiamento, o sucateamento das infraestruturas, as terceirizações, entre outras. Notase que diversas contrarreformas impediram que essa política se materializasse conforme previsto na CF/1988 e na Lei 8.080/1990. (CFESS, 2017).

O SUS vem sofrendo impactos da crise, em especial, na última década frente aos desafios e dificuldades para sua efetivação, destacam-se: a fragmentação do processo de trabalho e das relações entre os diferentes profissionais; pouco investimento na valorização e inclusão de trabalhadores e usuários no processo de produção de saúde e principalmente o desrespeitoaos direitos dos usuários.

Para Mattos (2001), apesar dos avanços conquistados com o SUS, o estrangulamento de recursos públicos e a difusão de determinadas ideias tornam o sistema vulnerável ao risco de distanciar-se de sua concepção original, o modelo de saúde privada instituído na década de 1990 se faz fortemente presente atualmente. Assiste-se a crescente mercantilização da saúde, ampliando-se o assistencialismo e refilantropização concomitante à desresponsabilização do Estado. Essas investidas, de cunho neoliberal, refletem na saúde por meio da restrição do financiamento público, 
ênfase em programas focais, incentivo a dicotomia entre ações curativas e preventivas. (CFESS, 2010).

Desde o seu nascedouro, na CF/1988, o SUS vem vivendo imensos boicotes, destes, Matos (2020) cita o desfinanciamento público, a exemplo da Emenda Constitucional (EC) no 95/2016, que congelou por 20 anos o investimento da saúde e na educação, a sistemática alteração do seu modelo de gestão para perspectivas privatizantes, e o avanço do setor privado criando uma ideologia da impossibilidade da assistência pública à saúde de qualidade, expulsando amplos segmentos que, iludidos com a compra do plano de saúde, julgam não ser fundamental a defesa do SUS. (Matos, 2014; Bravo et al, 2015).

Nesse sentido, foi criada a Política Nacional de Humanização - PNH em 2003, a fim de colocar em prática os princípios do SUS e produzir mudanças naforma de gerir e cuidar, estimulando a comunicação entre gestores, trabalhadores e usuários para a construção coletiva ao enfrentamento de relações de poder, que muitas vezes levam a práticas desumanizadas. A PNH surgiu com o objetivo de oferecer alterações no modelo assistencial aos usuários do SUS, com uma proposta de "[...] uma política incentivadora do protagonismo dos sujeitos e da ampliação da atenção integral da saúde, promovendo a intersetorialidade" (BRASIL, 2010).

Partindo desta perspectiva, a humanização então, é percebida como política pública estruturando-se na valorização dos diferentes sujeitos envolvidos na atenção à saúde. Ressalta-se às mudanças nos modelos de atenção e gestão a partir da identificação das necessidades sociais. A humanização vem sendo algo essencial no trabalho dos profissionais de saúde, nos programas e projetos que envolvem ações de educação, promoção e prevenção em saúde. Haja vista, a importância de realçar a dimensão humana no cuidado da dor e do sofrimento, principalmente no âmbito hospitalar, como abordaremos no próximo tópico.

\section{O trabalho de assistentes sociais à humanização em uma unidade de cuidados paliativos}

Frente às discussões acima, salienta-se a importância da inserção do assistente social na área da saúde, em especial, no que se refere aos cuidadospaliativos. Ressaltase às necessidades de saúde como "[...] produtos das relações sociais e destes com o meio físico, social e cultural" (Nogueira; MIoto, 2009: 229). De modo que esse

Iluminuras, Porto Alegre, v. 22, n. 58, p. 402-423, dezembro, 2021 
profissional reconheça os (DSS) para compreender o processo saúde-doença dos usuários e o sofrimento das famílias.

Entende-se que cabe ao Serviço Social "[...] formular estratégias que busquem reforçar ou criar experiências nos serviços de saúde que efetivem o direito social à saúde" (BRAVO; MATOS, 2009: 213). Assim, os assistentes sociais devem construir alternativas e respostas que ampliem o atendimento às demandas apresentadas pelos usuários e seus familiares, a fim de favorecer a equidade e justiça social na saúde.

Os cuidados paliativos têm como premissa oferecer atenção integral aossujeitos, a fim de compreendê-los nas múltiplas necessidades e instâncias queregem e compõem suas vidas (FERREIRA, 2017). No âmbito do Serviço Socialdeve ser uma intervenção baseada nas premissas éticas, e pela humanização da sua prática, além dos seus conhecimentos técnicos, teóricos e metodológicos. Martinelli (2007) pontua sobre os sentimentos e valores, buscando uma ação de qualidade e o reconhecimento do usuário como um sujeito de direito.

Faz parte do processo de trabalho do assistente social a busca pela garantia de acolhimento humanizado aos pacientes e familiares que recebem a abordagem de cuidados paliativos. Sobre humanização parte-se da simplificação do termo que para Pessini e Bertachini (2004: 15) consiste em:

Humanizar é garantir à palavra a sua dignidade ética. Ou seja, para que o sofrimento humano e as percepções de dor ou de prazer sejam humanizadas, é preciso que as palavras que o sujeito expressa sejam reconhecidas pelo outro. É preciso, ainda, que esse sujeito ouça, do outro, palavras de seu reconhecimento. É pela linguagem que fazemos as descobertas de meios pessoais de comunicação com o outro (Pessini e Bertachini, 2004: 15).

A humanização torna-se uma estratégia metodológica à produção e gestão de cuidados em saúde, tais como: integralidade, satisfação do usuário, necessidades de saúde, qualidade da assistência, gestão participativa, protagonismo dos sujeitos, resolutividade, e ainda, visa à melhoria da qualidade de vida dos mesmos. Dito isto, acerca do espaço sócio ocupacional onde foram realizadas as abordagens contidas neste artigo, representa um espaço de humanização e referência em saúde.

Na medida em que o Hospital de Clínicas de Porto Alegre (HCPA) é uma instituição pública, geral e universitária, pertencente à rede de hospitais universitários do Ministério da Educação (MEC), e é vinculado academicamente à Universidade 
Federal do Rio Grande do Sul (UFRGS). Considerado um hospital-escola, sua missão não fica restrita apenas à assistência à saúde, mas também à formação de profissionais de nível médio, graduação e pós-graduação.

Durante o estágio, persistia a ideia de que pacientes fossem transferidos do (HCPA) a Unidade Álvaro Alvim (UAA) apenas para morrer, representadas nas falas a seguir: "[...] hospital da morte”, “[...] a gente veio pra cá, porque não tem mais o que fazer" eram comuns de se ouvir, ou como na fala do familiar E.* (27 anos), que acompanhava o pai A.* , (60 anos), com câncer de pulmão:

Fiquei triste, sem saber se deveríamos ter vindo pra cá, mas veio a primeira funcionária, sorriu e perguntou como estávamos, aquele sorriso e a atenção dela, fez toda a diferença. (Rosa, 2019, Extraído do Diário de Campo).

Escutamos frequentemente a frase "[...] não tem mais o que fazer", quandoo paciente chegava até essa unidade, porém para reverter tal entendimentodos mesmos e seus familiares sobre cuidados paliativos, informávamos que "Há muito o que fazer", mesmo que não houvesse um tratamento curativo. Isso exigia uma abordagem particular no leito do paciente, por vezes, a intervenção era extensiva aos familiares logo no primeiro atendimento. Nesta abordagem era entregue o folder informativo da unidade e esclarecidos os cuidados paliativos, o que facilitava o início do diálogo a respeito do tema e o entendimento da família e paciente sobre o mesmo.

Nesta perspectiva, o assistente social desempenha o processo de trabalho, tanto em relação à orientação e quanto na reflexão junto a estes sujeitos, facilitando a compreensão sobre o que são os cuidados paliativos. Ou seja, esclarecendo-os tanto sobre a organização da família frente a realidadede agravo no estado de saúde quanto acolhendo todos os sujeitos implicados. Por vezes, esses precisavam de auxílio para se reorganizar e receber o paciente após a alta segura, através do acesso de recursos disponíveis, assistidos pela rede socioassistencial de origem. Também, para reorganizar os momentos de despedidas de seu membro no domicílio, ou ainda, na unidade hospitalar, quando a permanência do ponto de vista social, se fazia necessário. Haja vista, que o cuidado paliativo é um direito humano e um componente essencial na integralidade e longitudinalidade no campo da saúde. Trata-se de um acompanhamento centrado no paciente e em seus familiares durante o curso da doença até o final da vida, para priorizar o bem-estar e oconforto. 
Portanto, deve ser fornecido em qualquer ambiente de cuidados desaúde, incluindo: clínicas ambulatoriais, hospitais, hospedarias, instituições de longa permanência de idosos, centros comunitários de saúde e nas residências

dos pacientes. (GOMESZ-Batiste; Connor, 2017).

Diante de algumas situações, faz-se importante na intervenção do assistente social as reuniões familiares, na unidade de cuidados paliativos para dirimir dúvidas sobre o quadro clínico do usuário, funcionamento da unidade, e verificar como a família estava lidando com o processo de agravamento da doença. Na medida em que é importante considerar o desejo do paciente, inclusive participar ou não desta reunião.

Para Boff (2012), o cuidado somente surge quando a existência de alguém tem importância para o outro; é quando então passamos a nos dedicar a ele, dispondo-nos a participar de seu destino, de suas buscas, de seus sofrimentos, enfim, de sua vida. Porém, para algumas famílias como visto em campo de estágio, a dificuldade é mais proeminente, pois seus vínculos são frágeis, ou até inexistentes.

No cotidiano de trabalho no âmbito hospitalar conforme Martinelli (2011), geralmente trabalhamos com pessoas fragilizadas que nos pedem um gesto humano: um olhar, uma palavra, uma escuta atenta, um acolhimento, para que possam se fortalecer. Durante o estágio, era comum recebermos agradecimentos referente o acolhimento humanizado aos pacientes e familiares/cuidadores. Por vezes, os mesmos não compreendiam que essa unidade era parte do HCPA, e nem que teriam acesso a tantos recursos pelo SUS, o que demonstra a importância e necessidade de educação em saúde.

Chama atenção, que todas as datas comemorativas na UAA, recebiam decoração alusiva e dispunha de atividades diversas, contribuindo para um ambiente mais acolhedor e descontraído. Desta forma, transmitia sensação de que durante o processo de adoecimento dos que ali estavam, também era passível ressignificar tais momentos. Também havia, além da ambiência da unidade, o acolhimento aos grupos, semanalmente, intitulados como o grupo momento de escuta ${ }^{7}$ e grupo de enlutados ${ }^{8}$, e ainda, o programa Pet Terapia, onde as famílias tinham liberação para levar os animais de estimação dos pacientes internados, para promover a despedidas entre esses.

Assim, a dimensão teórico metodológico refere-se aos saberes, conhecimentos, referenciais, que subsidiam a prática profissional. Tendo em vista o trabalho nesse campo de estágio, foi necessária a compreensão da política de saúde, teorizações sobre cuidados paliativos, embasamento nas legislações específicas, para fundamentar os 
posicionamentos e as intervenções. Isso tudo, norteada pela reflexão crítica, reflexiva, propositiva acerca da realidade dos pacientes.

Essa dimensão favoreceu a competência técnico operativa, a medida que propiciou as habilidades para materializar a intervenção, a partir das entrevistas individuais, mediações e reuniões com as famílias, grupos, contatoscom a rede, registros de documentos, entre outros. Segundo Tavares (2020), esta dimensão perpassa pela análise da realidade, interpretando-a, a partir de aspectos políticos, sociais, éticos, econômicos e culturais.

Ressalta-se a contribuição dos assistentes sociais conjuntamente com os pacientes e seus familiares na busca de alternativas frente às questões que surgiam. Nessa direção, os assistentes sociais necessitam de "[...] fundamentos teórico metodológicos, conhecimentos e saberes interventivos, habilidades técnico profissionais, procedimentos teórico metodológicos e de uma perspectiva ética com clara orientação estratégica" (Guerra, 2012: 41).

Neste contexto, destaca-se a dimensão ético-política que compõe os fundamentos do trabalho do assistente social junto com as dimensões mencionadas, com base nos princípios e valores contidos no Código de Ética profissional. Para Tavares (2020), a defesa de uma nova ordem societária, exige a luta pela democracia, e a socialização da participação política. Portanto, foi perceptível a relevância desta dimensão, através da apropriação da lei que regulamenta a profissão e os parâmetros de atuação na política de saúde, que contribuíram para a efetivação do processo de trabalho.

Para Vasconcelos (1997), o assistente social busca contribuir com sua ação, na produção de uma nova sociedade, que favoreça a igualdade e a redistribuição de riqueza, uma sociedade democrática, ao articular sua prática aos interesses, desejos e necessidades dos usuários. Por fim, frente ao desafiode construir um processo reflexivo acerca dos cuidados paliativos, a partir de relações humanizadas no ambiente hospitalar com pacientes e familiares demonstra-se a importância da conversação dialógica entre todos os sujeitos envolvidos.

\section{Considerações}

Esse relato de experiência deu vistas ao trabalho de assistentes sociais em uma unidade de cuidados paliativos, a partir do reconhecimento do objeto, ou seja, as

Iluminuras, Porto Alegre, v. 22, n. 58, p. 402-423, dezembro, 2021 
expressões da questão social manifestadas na vida dos pacientes e seus familiares/cuidadores. Disso, à conversação dialógica sobre finitude representou uma intervenção potencializadora no campo de estágio.

Embora os avanços desde a CF/1988, o SUS, a PNH, que possibilitaramo acesso à atendimentos na política de saúde, em espaços públicos como a UAA, ainda existem desafios e limites institucionais. A atual conjuntura, deflagra o sucateamento desta política, assim como outras, frente a crise do capitalismo, desassistência aos trabalhadores de saúde e usuários, subfinanciamento, entre outros. Prova disso foi o fechamento da UAA, e consequentemente da unidade de cuidados paliativos, como um dos resultadosdeste impacto da crise.

Isso rebate diretamente nos cuidados paliativos, que deveriam beneficiar não apenas quem está no curso final de uma doença grave, mas todos que vivenciam uma doença que ameace a vida, desde o seu diagnóstico. Soma-se o desconhecimento acerca do tema por profissionais e usuários, como mencionado neste artigo. Assim, demonstra-se a importância do conhecimento acerca dos cuidados paliativos, principalmente, por assistentes sociais que estão inseridos na política de saúde, e que terão este assunto cadavez mais presente no seu cotidiano de trabalho.

Contudo, na sociedade brasileira tratamos a morte como um tabu, por isso, as informações colhidas durante a experiência do estágio, e trazidas pelos pacientes, familiares/cuidadores, possibilitaram essa reflexão acerca dos cuidados no final da vida. Nesse contexto, precisamos transpor as demandas burocráticas para uma perspectiva humanizadora, de acolhimento, de autonomia, o luto destes usuários e seus familiares. Haja vista, que a autonomia dos pacientes corresponde às suas escolhas com relação ao tratamento de saúde.

Com isso, é necessário destacar que o assistente social inserido no contexto de cuidados paliativos, como visto em campo, encontra desafios e possibilidades no cotidiano do seu processo de trabalho. Então, refletir acerca do processo de morrer e viabilizar essa conversação dialógica junto aos usuários compõem as atribuições dos assistentes sociais nesta unidade de cuidados paliativos.

\section{Referências}

ABEPSS. Diretrizes Gerais para o Curso de Serviço Social. 1996.

ANDRADE, Leticia. (Org). Cuidados Paliativos e Serviço Social: Um exercíciode 
coragem. $1^{\mathrm{o}}$ ed. Volume 2. Holambra: Ed Setembro, 2017.

ANDRADE, Leticia. (Org). Trajetórias no limiar da vida e da morte: cuidados paliativosna assistência domiciliar. 2007. 199 f. Tese (Doutorado em Serviço Social), Pontifícia Universidade Católica de São Paulo - PUC-SP, São Paulo, 2007.

ARANTES. Ana Claudia Quintana. A morte é um dia que vale a pena viver. Rio de Janeiro: Editora Sextante, 2019.

ARIÈS, Philippe. História da morte no Ocidente: da Idade Média aos nossos dias. Trad. de Priscila Viana de Siqueira. Prefácio de Jacob Pinheiro Goldberg. Rio de Janeiro: Ediouro, 2003.

BOFF, Leonardo. Saber cuidar: ética do humano - compaixão pela terra. 18. ed. Petrópolis: Vozes, 2012.

BOSCHETTI, Ivanete. Seguridade social no Brasil: conquistas e limites à sua efetivação. Brasília, DF: UnB/CFESS. 2009.

BRASIL. Constituição (1988). Constituição da República Federativa do Brasil. Brasília, DF: Centro Gráfico, 1988.

BRASIL. Lei $n^{\circ}$ 8.080, de 19 de setembro de 1990. Dispõe do Sistema Único de Saúde. 1990.

BRASIL. Ministério da Saúde. Secretaria-Executiva. Núcleo Técnico da Política Nacional de Humanização. Humaniza SUS: grupo de trabalho de humanização: GTH / Ministério da Saúde, Secretaria-Executiva, Núcleo Técnico da Política Nacional de Humanização. Brasília: Ministério da Saúde, 2004.

BRASIL. Ministério da Saúde. Secretaria de Atenção à Saúde. Núcleo Técnico da Política Nacional de Humanização. Política Nacional de Humanização / Ministério da Saúde, Secretaria de Atenção à Saúde, Núcleo Técnico da Política Nacional de Humanização. 1. ed. Brasília: Editora do Ministério da Saúde, 2013.

BRASIL. Ministério da Saúde. Secretaria de Atenção à Saúde. Política Nacional de Humanização. Atenção Básica / Ministério da Saúde, Secretaria de Atenção à Saúde, Política Nacional de Humanização. Brasília: Ministério da Saúde, 2010.

BRAGA, J.C.S.; PAULA, S.G. Saúde e Previdência. Estudos de Política Social. São Paulo: HUCITEC, 1986.

BRAVO, Maria Inês Souza et al (org.). A mercantilização da saúde em debate: as Organizações Sociais no Rio de Janeiro. Rio de Janeiro: UERJ, Rede Sirius, 2015.

BRAVO, Maria Inês Souza et al (org.). Serviço Social e Saúde: Formação etrabalho profissional. $4^{\mathrm{a}}$ ed. São Paulo. Editora Cortez, 2009.

BRAVO, Maria Inês Souza; MATOS, Maurílio Castro. Projeto ético-político do Serviço Social e sua relação com a reforma sanitária: elementos para o debate. In: MOTA, Ana 
Elisabete et al (org.). Serviço Social e Saúde: formação e trabalho profissional. $4^{\mathrm{a}}$ ed. São Paulo: Editora Cortez, 2009.

CARVALHO, J. M. Cidadania no Brasil. O longo caminho. 3. ed. Rio de Janeiro: Civilização Brasileira, 2002.

COMISSÃO NACIONAL SOBRE OS DETERMINANTES SOCIAIS DA SAÚDE (CNDSS). Carta aberta aos candidatos à Presidência da República. Setembro de 2006.

CONSELHO FEDERAL DE SERVIÇO SOCIAL. Código de Ética do/aAssistente Social. 10. ed. rev. e atual., Brasília: CFESS, 2012.

CONSELHO FEDERAL DE SERVIÇO SOCIAL. CFESS Manifesta: Dia mundial da Saúde. Brasília, abril2017.

CONSELHO FEDERAL DE SERVIÇO SOCIAL. Parâmetros para a atuação de assistentes sociais napolítica de saúde. Brasília: CFESS, 2010.

COUTO, Berenice Rojas. Formulação de projeto de trabalho profissional. In: Conselho Federal de Serviço Social - CFESS; Associação Brasileira em Ensino e Pesquisa em Serviço Social - ABEPSS. Brasília: 2009.

DU BOULAY, Shirley. Changing the face of death. The story of Cicely Saunders.2.ed. Great Britain: Brightsea Press. 2007.

ESCOREL, Sarah. História das Políticas de Saúde no Brasil de 1964 a 1990: do Golpe Militar à Reforma Sanitária. Políticas e Sistemas de Saúde no Brasil. $2^{\text {a }}$ ed. Rio de Janeiro: Editora Fiocruz/Centro Brasileiro de Estudos de Saúde; 2012.

GIL, A. C. Como elaborar projetos de pesquisa. 3. ed. São Paulo: Atlas, 1991.

GIOVANELLA, Lígia et al. (org.). Políticas e Sistema de Saúde no Brasil. 2. ed.Rio de Janeiro: Editora FIOCRUZ, 2012.

GOMESZ-BATISTE X, CONNOR S (ed.). Building Integrated Palliative Care Programs and Services, The Worldwide Hospice Palliative Care Alliance. Mai, 2017.

GUERRA, Yolanda. A Dimensão Técnico Operativa no Serviço Social: desafios contemporâneos. Juiz de Fora: Editora UFJF, 2012.

GUERRA, Yolanda. A instrumentalidade do Serviço Social. $10^{\mathrm{a}}$ ed. São Paulo:Cortez, 2013.

IAMAMOTO, M. V. Serviço Social em tempo de capital fetiche. São Paulo:Cortez, 2007.

IAMAMOTO, M. V. As dimensões ético-políticas e teórico-metodológicas no Serviço Social contemporâneo, Universidade da Costa Rica, 2004.

KOVÁCS, M.J. Perdas e o Processo de Luto. In: INCONTRI, D.; SANTOS, F.s. (org.). 
A arte de morrer: visões plurais. v. 1. Bragança Paulista: Comenius, 2007.

KÚBLER-ROSS, Elisabeth. Sobre a morte e o morrer. [s.l.]: Martins Fontes, 1985.

MARTINELLI, M. L. O exercício profissional do assistente social na área da saúde: algumas reflexões éticas. Serviço Social \& Saúde, Campinas, v. 6, n. 6, maio de 2007.

MARTINELLI, M. L. O trabalho do assistente social em contextos hospitalares: desafios cotidianos. Serviço Social e Sociedade, São Paulo. n. 107. 2011.

MARANHÃO, José Luiz de Souza. O que é a morte. Coleção Primeiros Passos. São Paulo: Brasiliense, 1998.

MATOS, Maurílio Castro de. A pandemia do coronavírus (COVID-19) e o trabalho de assistentes sociais na saúde. CRESS, Espírito Santo, 2020.

MATSUMOTO, Dalva Yukie. Cuidados Paliativos: conceito, fundamentos e princípios. In: CARVALHO, Ricardo Tavares; PARSONS, Henrique Afonseca (org.). Manual de Cuidados Paliativos - ANCP. $2^{\text {a }}$ ed. Porto Alegre: Ed. Sulina,2012.

MATTOS, R.A. Os sentidos da integralidade: algumas reflexões acerca de valores que merecem ser definidos. In: PINHEIRO, R.; MATTOS, R.A. (ed.). Os sentidos da integralidade na atenção e no cuidado à saúde. Rio de Janeiro: UERJ-IMS-Abrasco, 2001.

MIOTO, Regina Célia Tomasoto; LIMA, Telma Cristiane Sasso De. A dimensão técnico operativa do Serviço Social em foco: sistematização de um processo investigativo. Revista Textos \& Contextos, Porto Alegre v. 8 n.1. jan./jun. 2009.

NOGUEIRA, V. M. R.; MIOTO, R. C. T. Desafios atuais do Sistema Único de Saúde - SUS e as exigências para os assistentes sociais. In: MOTA, E. E. et al. (org.). Serviço Social e saúde: formação e trabalho profissional. São Paulo: Cortez, 2006.

ONCOGUIA, Instituto. Nutrição e Câncer. 13 de agosto de 2018. Disponível em: <http://www.oncoguia.org.br/>. Acesso em: 28 de abril de 2021.

ORGANIZAÇÃO MUNDIAL DA SAÚDE. National cancer control programmes: policies and managerial guidelines. 2. ed. Geneva: OMS, 2017.

PAIM, J.S et al. O sistema de saúde brasileiro: história, avanços e desafios. Saúde No Brasil. v. 377, n. 9779, maio de 2011.

PARKES, Colin Murray. Luto: Estudos Sobre A Perda Na Vida Adulta. [s.l.]: Ed. Summus, 1998.

PESSINI, L. Humanização da dor e sofrimento humanos na área da saúde. Revista Bioética, v. 10, 2000.

PESSINI, L.; BERTACHINI, L. Humanização e Cuidados Paliativos. $2^{\mathrm{a}}$ ed. São Paulo: Loyola. 2004. 
POLIGNANO, M. V. História das Políticas de Saúde no Brasil-Uma pequena revisão, [s.l.], 2001. Disponível em: <http://medicinadeemergencia.org/wpcontent/uploads/2015/04/historia-das-politicas-de-saude-no-brasil-16-030112-SESMT.pdf>. Acesso em nov. 2021.

REIS, D. et al. Políticas Públicas no Brasil: SUS e Pactos Pela Saúde, Módulo Gestor; Especialização em Saúde Familiar. 2010.

ROSA, Tainara da. Diário de Campo: estágio curricular em Serviço Social da Universidade Luterana do Brasil. Canoas: ULBRA, agosto de 2019/março de 2020.

SCHEUNEMANN. Arno Vorpagel et al. Processo de Trabalho no Serviço Social. Canoas: Ed. ULBRA, 2010.

SLAIBI, M.C.B.G. O direito fundamental à saúde. BIS, Bol. Inst. Saúde (Impr.), v.12, n.3, 2010.

TAVARES, Rosilene A. As dimensões teórico metodológica, técnico operativa e éticopolítica do serviço social no trabalho do assistente social. Revista Serviço Social em Perspectiva, v. 4, Edição Especial, março de 2020.

VASCONCELOS, Ana Maria. Serviço Social e Práticas Democráticas na Saúde. In: MOTA, Ana Elizabete et al. (org.). Serviço Social e Saúde: Formação e Trabalho Profissional. $4^{\text {a }}$ ed. São Paulo: Editora Cortez, 2009.

VASCONCELOS, Ana Maria. Serviço Social e prática reflexiva. Revista Em PautaFaculdade de Serviço Social da UERJ, Rio de Janeiro, n. 10, set. 1997.

Data de submissão: 12 de setembro de 2021

Data de publicação: 20 de dezembro de 2021 